\title{
POTENSI PESISIR UTARA BANTEN SEBAGAI PENGHASIL GARAM
}

\section{THE POTENTIAL OF NORTH COAST OF BANTEN AS SALT PRODUCER}

\author{
Yusniah Anggraini ${ }^{1)}$ dan Aris Munandar ${ }^{2}$ \\ ${ }^{1)}$ Badan Perencanaan Pembangunan Daerah Provinsi Banten \\ Jl. Syeh Nawawi Albantani KP3B Palima Curug Kota Serang \\ ${ }^{2)}$ Fakultas Pertanian, Universitas Sultan Ageng Tirtayasa \\ J1. Raya Jakarta KM. 04. Pakupatan Serang. \\ E-mail: yusnia.anggraini@gmail.com
}

\begin{abstract}
ABSTRAK
Ketimpangan antara luasan lahan potensial dibandingkan dengan lahan yang telah dimanfaatkan merupakan peluang untuk peningkatan produksi garam melalui perluasan tambak garam di Indonesia. Selain peluang, berbagai masalah yang teridentifikasi dalam upaya pencapaian swasembada garam adalah rendahnya produktivitas lahan yang terkait dengan kurangnya pengembangan teknologi, sumberdaya manusia, penyediaan sarana dan prasarana produksi garam, serta aspek tata niaga. Hal yang lebih penting lagi, diperlukan ketersediaan data yang valid untuk dapat menentukan angka kebutuhan garam yang sebenarnya (riil), baik untuk kebutuhan konsumsi rumah tangga maupun industri. Hal ini terkait dengan kuantitas garam yang harus tersedia agar swasembada garam dapat tercapai. Penelitian ini bertujuan untuk menentukan kelayakan wilayah untuk menjadi sumber penghasil garam dan inovasi teknologi dalam pembuatan garam di Provinsi Banten. Hasil penelitian menunjukkan bahwa wilayah perairan utara Provinsi Banten memiliki potensi untuk pengembangan produksi garam. Potensi tersebut ditunjukkan dari hasil pengujian kualitas air dan kajian wilayahnya terutama tambak-tambak yang sudah idle.Pengembangan produksi garam di Provinsi Banten perlu diberikan sentuhan inovasi teknologi agar dapat meningkatkan produktivitas dan kualitas garam yang dihasilkan baik dan sesuai Standar Nasional Indonesia (SNI). Inovasi teknologi yang sesuai dengan wilayah Banten adalah produksi garam dengan sistem termal dan Teknologi Ulir Filter (TUF). Selain itu, pengolahan limbah dari produksi garam juga dilakukan melalui teknologi Bittern yang dapat dijadikan sebagai bahan baku industri.
\end{abstract}

Kata Kunci : Pengembangan potensi,Pesisir Utara Banten, garam.

\section{ABSTRACT}

To increase the production of salt through the expansion of salt ponds in Indonesia, one of the opportunities is to compare inequality between the potential land area and the land that has been used. In addition to this opportunity, a wide range of issues have been identified in the efforts to achieve salt self-sufficiency, including the low productivity of the land associated with the lack of development of technology, human resources, supply of salt production facilities and infrastructure, as well as aspects of the trade system. More importantly, the availability of valid 
data required to determine the real needs of salt, both for household and industrial consumption. This actual demand is related to the quantity of salt that must be provided in order to achieve self-sufficiency. This study aims to determine the feasibility of area to be considered as a source of salt, in addition to technological innovation in the manufacturing of salt in Banten Province. The results showed that the northern regions of Banten province has the potential for salt production expansion. The potential is derived from the results of seawater quality testing and review of idle ponds. To enhance the quantity and quality of Banten province salt production, a touch of technological innovation needs to be applied in order to comply with the Indonesian National Standard (SNI). Technological innovations that are suitable to Banten Province characteristics are the thermal system and Screw Technology Filter (TUF), in addition to Bittern technology, the processing of salt waste for industrial raw materials.

Keywords: Development potential, the North Coast of Banten, salt

\section{PENDAHULUAN}

Garam telah dicanangkan sebagai komoditas pangan strategis dalam "Feed Indonesia, Feed the World II" tahun 2012, sehingga Indonesia membutuhkan strategi untuk mewujudkan swasembada garam. Namun, berdasarkan data dari Kementerian Perdagangan, produksi garam nasional hingga November 2011, baru mencapai 48,3\% dari kebutuhan garam dalam negeri. Potensi lahan tambak garam di Indonesia diperkirakan 34.000 ha, tetapi hanya sekitar 20.000 ha $(60 \%)$ yang telah dimanfaatkan untuk produksi garam. Lahan yang telah dimanfaatkan tersebut tersebar di beberapa provinsi yaitu Aceh, Jawa Barat, Jawa Tengah, Jawa Timur, Bali, NTB, NTT, Sulawesi Selatan dan Sulawesi Tenggara. Pulau Madura yang merupakan lumbung produksi garam terbesar nasional, mempunyai lahan garam yang telah dieksploitasi seluas 15.347 ha.

Kementrian Kelautan dan Perikanan (KKP) telah melakukan beberapa langkah strategis untuk mencapai swasembada garam. Pada tahun 2011, Pemerintah melaksanakan Program Pemberdayaan Usaha Garam Rakyat (PUGAR) yang merupakan kegiatan pemberdayaan masyarakat petambak garam rakyat. Program ini bertujuan untuk mengurangi kemiskinan dan meningkatkan kesempatan kerja serta mencapai swasembada garam nasional. Hanya saja, program ini dinilai belum dapat mendorong petambak garam untuk meningkatkan kuantitas maupun kualitas produksi garam. Oleh karena itu, diperlukan upaya komprehensif sehingga PUGAR secara efisien dan efektif mendorong petambak garam meningkatkan kuantitas dan 
kualitas produksinya dalam rangka mencapai swasembada garam. Hal ini terkait dengan kuantitas garam yang harus tersedia agar swasembada garam dapat tercapai.

Salah satu daerah yang berpotensi untuk dikaji sebagai wilayah yang dapat memproduksi garam adalah di wilayah pesisir Utara Banten. Provinsi Banten memiliki luas perairan 11.134,22 km², panjang pantai $509 \mathrm{~km}$, pembudidaya sebanyak 28.480 orang, luas lahan budidaya 16.725 Ha, laut $835 \mathrm{Ha}$, dan tambak 10.358 Ha. Namun, sampai saat ini ketersediaan garam di Provinsi Banten masih menjadi kendala. Masih ada garam yang ditemukan di Provinsi Banten tidak layak untuk di konsumsi. (Prihantono et al 2014). Hal ini harus menjadi perhatian serius pemerintah daerah setempat untuk dapat memenuhi ketersediaan garam dari segi kualitas, kuantitas dan kontinuitas. Dengan luasnya area perairan di Provinsi Banten, pemerintah bisa melakukan kajian secara mendalam untuk melihat potensi daerah sebagai sumber penghasil garam.

\section{METODE PENELITIAN}

Penelitian ini dilaksanakan di Pesisir utara Provinsi Banten. Pengambilan data dilakukan pada sembilan stasiun. Pemilihan stasiun didasarkan pada letak terhadap permukaan air laut, topografi, sifat fisik tanah, adanya tambak idle, kondisi kualitas air, mewakili pesisir utara Banten. Terdapat 6 Stasiun kajian yaitu Karangantu, Pulau Dua, Domas, Lontar, Tanjung Kait dan Tanjung Pasir.

Keberhasilan pembuatan garam sangat ditentukan oleh kualitas air laut sebagai bahan baku utama (Suhelmi et al 2013). Oleh karena itu, untuk mengetahui potensi tambak garam di wilayah pesisir utara banten maka dilakukan pengambilan sampel air laut. Sampel air laut diambil dari wilayah perairan utara Provinsi Banten.

Titik pengambilan sampel air laut di wilayah utara Provinsi Banten dilakukan di enam stasiun, yaitu Karangantu (stasiun 1), Pulau Dua (stasiun 2), Domas (stasiun 3) Lontar (stasiun 4), Tanjung Kait (stasiun 5) dan Tanjung Pasir (stasiun 6). Penentuan lokasi pengambilan sampel dilakukan berdasarkan persyaratan tambak garam dan kondisi tambak idle pada wilayah tersebut. Pengambilan sampel di Stasiun 1 dilakukan di Karangantu pada titik koordinat yaitu 06 01'53.73" LS, 10609'13.11" BT (elevasi $23 \mathrm{~m}), 06^{\circ} 01^{\prime} 30.87^{\prime \prime} \mathrm{LS}, 106^{\circ} 09^{\prime} 22.14$ " BT (elevasi $25 \mathrm{~m}$ ) dan $06^{\circ} 01^{\prime} 27.87^{\prime \prime}$ LS 106 09'21.25" BT (elevasi $20 \mathrm{~m}$ ).

Pengambilan sampel pada Stasiun 2 dilakukan di Pulau Dua, tepatnya pada 
koordinat $06^{\circ} 01^{\prime} 47.98^{\prime \prime} \mathrm{LS}, 106^{\circ} 11$ ' $55,88^{\prime \prime}$

BT (elevasi $16 \mathrm{~m}), 06^{\circ} 01^{\prime} 11.58^{\prime \prime} \mathrm{LS}$, $106^{\circ} 11 ' 53.11 "$ BT (elevasi $16 \mathrm{~m}$ ) dan $06^{\circ} 01^{\prime} 03.45^{\prime \prime}$ LS 106 11 '43.40" BT (elevasi 17 m). Pulau Dua merupakan kawasan cagar alam, dimana pada wilayah tersebut juga banyak terdapat tambak ikan bandeng. Kondisi tambak tersebut beberapa sudah tidak dimanfaatkan sebagai lokasi budidaya. Pengambilan sampel pada Stasiun 3 pada koordinat $05^{\circ} 58^{\prime} 13.96^{\prime \prime} \operatorname{LS} 106^{\circ} 15^{\prime} 45.50$ " BT (elevasi 16 m) dan S 0557'56.69' LS, $106^{\circ} 15^{\prime} 44.77^{\prime \prime}$ BT (elevasi $17 \mathrm{~m}$ ), tepatnya di Desa Domas.

Desa Lontar, Kecamatan Tirtayasa menjadi lokasi selanjutnya, dimana wilayah tersebut merupakan salah satu sentra rumput laut jenis Kappaphycus alvarezii. Selain itu, pada lokasi tersebut juga banyak terdapat tambak ikan bandeng (Chanos chanos) yang tidak dimanfaatkan. Tambak tersebut dimanfaatkan sebagai lokasi penambangan pasir, padahal masih dapat digunakan sebagai tambak garam. Lokasi pengambilan sampel dilakukan pada koordinat $05^{\circ} 52^{\prime} 07.59^{\prime \prime} \mathrm{LS}$, $106^{\circ} 17^{\prime} 55.43^{\prime \prime}$ BT (elevasi $10 \mathrm{~m}$ ).

Tabel 1 Kualitas air di perairan utara Banten

\begin{tabular}{|c|c|c|c|c|c|c|c|c|c|c|}
\hline \multirow{2}{*}{ No } & \multirow{2}{*}{ Parameter } & \multirow{2}{*}{\multicolumn{2}{|c|}{ Satuan }} & \multicolumn{6}{|c|}{ Stasiun } & \multirow{2}{*}{$\mathbf{B M}$} \\
\hline & & & & 1 & 2 & 3 & 4 & 5 & 6 & \\
\hline 1 & Sulfat $\left(\mathrm{SO}_{4}\right)^{+}$ & $\mathrm{mg} / \mathrm{L}$ & $10.00 / \mathrm{T}$ & 1619.14 & 1164.79 & 1283.20 & 1284.42 & 1261.23 & 1352.78 & \\
\hline 2 & Khlorida $(\mathrm{Cl})^{+}$ & $\mathrm{mg} / \mathrm{L}$ & 4.00 & 19710.20 & 43958.00 & 34032.00 & 22688.00 & 15598.00 & 22688.00 & \\
\hline 3 & Boron $(\mathrm{B})^{+}$ & $\mathrm{mg} / \mathrm{L}$ & 0.010 & $<0.010$ & $<0.010$ & $<0.010$ & $<0.010$ & $<0.010$ & $<0.010$ & \\
\hline 4 & Fluorida $(\mathrm{F})^{+}$ & $\mathrm{mg} / \mathrm{L}$ & 0.010 & 1.022 & 1.520 & 1.733 & 1.627 & 1.947 & 1.893 & \\
\hline 5 & $\operatorname{Kadmium}(\mathrm{Cd})^{+}$ & $\mathrm{mg} / \mathrm{L}$ & 0.001 & $<0.001$ & $<0.001$ & $<0.001$ & $<0.001$ & $<0.001$ & $<0.001$ & 0.001 \\
\hline 6 & Timbal $(\mathrm{Pb})^{+}$ & $\mathrm{mg} / \mathrm{L}$ & 0.006 & $<0.006$ & $<0.006$ & $<0.006$ & $<0.006$ & $<0.006$ & $<0.006$ & 0.008 \\
\hline 7 & Natrium $(\mathrm{Na})$ & $\mathrm{mg} / \mathrm{L}$ & 0.005 & 4481.9 & 2701.998 & 2678.756 & 2698.717 & 2666.999 & 2661.256 & \\
\hline 8 & Kalium (K) & $\mathrm{mg} / \mathrm{L}$ & 0.005 & 283.37 & 231.806 & 202.239 & 193.964 & 215.56 & 222.018 & \\
\hline 9 & Magnesium (Mg) & $\mathrm{mg} / \mathrm{L}$ & 0.005 & 1284.7 & 887.584 & 840.956 & 850.948 & 805.985 & 734.378 & \\
\hline 10 & Kalsium $(\mathrm{Ca})$ & $\mathrm{mg} / \mathrm{L}$ & 0.005 & 784.77 & 783.295 & 730.597 & 737.525 & 698.434 & 684.579 & \\
\hline
\end{tabular}

Keterangan: *DL (Deteksi Limit); **Baku Mutu berdasarkan Kepmen-LH 51 Tahun 2004 
Wilayah perairan utara lainnya yang dijadikan sebagai lokasi pengambilan sampel adalah Kabupaten Tangerang, tepatnya di daerah Tanjung Kait dan Tanjung Pasir. Pada wilayah tersebut, mulai dari Mauk hingga Tanjung Pasir banyak terdapat tambak ikan dilakukan di Tanjung Pasir, dimana koordinatnya adalah $06^{\circ} 00^{\prime} 50.54$ ' LS $106^{\circ} 40{ }^{\prime} 39.25^{\prime \prime}$ BT (elevasi $16 \mathrm{~m}$ ). Berdasarkan hasil pengambilan sampel kualitas air di wilayah perairan utara Banten di 6 Stasiun dapat di lihat pada tabel 1.

Tabel 2 Komposisi air laut

\begin{tabular}{clc}
\hline No & Ion & Gr/kg Air Laut \\
\hline 1 & $\mathrm{Cl}^{-}$ & 19,354 \\
2 & $\mathrm{Na}^{+}$ & 10,77 \\
3 & $\mathrm{~K}^{+}$ & 0,399 \\
4 & $\mathrm{Mg}^{2+}$ & 1,29 \\
5 & $\mathrm{Ca}^{2+}$ & 0,4121 \\
6 & $\mathrm{SO}_{4}^{2-}$ & 2,712 \\
7 & $\mathrm{Br}^{-}$ & 0,0637 \\
8 & $\mathrm{~F}^{-}$ & 0,0012 \\
9 & $\mathrm{~B}^{+}$ & 0,0045 \\
10 & $\mathrm{Sr}^{2+}$ & 0,0079 \\
11 & $\mathrm{IO}_{3}$ & $6,0 \times 10^{-5}$ \\
\hline Sumber: Riley \& Skirrow $(1975)$
\end{tabular}

bandeng dan udang. Namun, pada kenyataannya tambak tersebut yang tidak dimanfaatkan sebagaimana mestinya. Wilayah Tanjung Kait dipilih sebagai Stasiun 5 untuk dilakukan pengambilan sampel kualitas air. Lokasi pengambilan dilakukan tepat pada koordinat $06^{\circ} 01^{\prime} 14.51^{\prime \prime} \mathrm{LS}$, 106 31' 44.78', BT (elevasi $18 \mathrm{~m}$ ). Pengambilan sampel pada Stasiun 6

\section{HASIL DAN PEMBAHASAN}

Secara keseluruhan, ke enam stasiun di perairan utara Banten mempunyai salinitas pada kisaran $32-34$ ppt. Menurut Adi et al (2007) salinitas air laut sebagai bahan baku garam adalah berkisar $25-35$ ppt. Selain salinitas, kualitas dan kandungan mineral air laut juga menentukan kandungan dan kualitas garam yang dihasilkan. Hasil analisis 
ion makro menunjukkan bahwa perairan di pantai utara Banten memiliki kandungan $\mathrm{Na}$ dan $\mathrm{Cl}$ lebih rendah bila dibandingkan dengan hasil yang didapat oleh Riley \& Skirrow (1975). Namun, kandungan sulfat yang lebih rendah memungkinkan garam yang dihasilkan dari perairan Pantai Utara Banten lebih baik. Hasil tersebut sesuai dengan penelitian yang dilakukan oleh Santosa (2014).

Selain itu, adanya kandungan logam berat berupa kadmium $(\mathrm{Cd})$ dan timbal $(\mathrm{Pb})$ pada perairan pantai utara Banten. Namun, kandungannya masih di bawah batas ambang normal untuk biota laut. Hal ini disebabkan karena wilayah utara merupakan kawasan industri sehingga dimungkinkan terjadi pembuangan limbah ke laut yang menyebabkan terjadi pencemaran di perairan laut. Pencemaran akibat aktivitas industri menyebabkan tingginya logam berat di perairan, jika $\mathrm{pH}$ perairan juga naik. Logam berat akan terakumulasi ke biota maupun manusia jika terkonsumsi secara terus menerus sehingga membahayakan kesehatan.

\section{a. Karangantu}

Salinitas pada Stasiun 1 (Karangantu) terukur dalam kisaran yang rendah.
Rendahnya salinitas pada titik pertama pengambilan sampel di Karangantu terjadi karena hujan sehari sehingga menyebabkan rendahnya kandungan salinitas. Perairan teluk Banten dalam beberapa tahun terakhir telah mendapat tekanan serius dari daratan dan perairan sekitarnya. Hal ini ditunjukkan dengan meningkatnya aktivitas industri, kawasan pemukiman penduduk, dan adanya penambangan pasir secara besar-besaran di dalam perairan teluk. Aktivitas tersebut menyebabkan tingginya pencemaran logam berat di perairan.

Berdasarkan hasil laboratorium kualitas air didapatkan bahwa kandungan logam berat di perairan Karangantu masih di bawah baku mutu. Prihatini (2013) menyatakan pencemaran lingkungan secara berlebihan dan terus menerus dapat menyebabkan penurunan $\mathrm{pH}$ (pengasaman) air laut. Proses tersebut mengakibatkan logam di dasar perairan dapat kembali lepas (terlarut) ke badan air, sehingga konsentrasinya di perairan melebihi batas ambang yang ditentukan.

\section{b. Pulau Dua}

Berdasarkan pengukuran salinitas, Pulau Dua memiliki berada pada kisaran yang baik untuk tambak garam. Pada stasiun 
tersebut, terdapat tambak-tambak idle yang sangat dimungkinkan untuk digunakan dalam pembuatan tambak garam dan jauh dari muara sungai. Namun, permasalahan terjadi karena di Pulau Dua merupakan kawasan cagar alam atau hutan konservasi sehingga dibutuhkan kerjasama antar pihak terkait.

\section{c. Domas}

Gambaran umum pada Stasiun 3 adalah terdapatnya tambak yang oleh masyarakat setempat digunakan untuk budidaya rumput laut dan ikan bandeng. Selain itu, pada daerah tersebut juga tersedia saluran tambak sehingga pada saat air laut pasang memudahkan aliran ke saluran dan petak tambak. Salah satu syarat tambak bisa dijadikan tambak garam adalah tanahnya harus kedap air (Adi et al 2007).

Berdasarkan hasil wawancara dengan masyarakat bahwa untuk mengetahui suatu tanah memiliki kekedapan tinggi adalah terdapatnya rumput teki (Cyperus rotundus). Keberadaan rumput teki di areal tambak menandakan kondisi tanah adalah liat dan berpasir yang mempunyai kemampuan untuk menahan air (Harjadi et al 2014). Sedangkan untuk pembenihan garam menggunakan tanah liat yang dapat menekan resepan air (kebocoran). Permasalahan lainnya adalah tingginya endapan lumpur dan banyaknya serasah dari hutan mangrove yang akan menyebabkan turunnya kualitas garam yang dihasilkan.

\section{d. Lontar}

Berdasarkan observasi langsung di lapangan didapatkan, bahwa daerah tersebut mengalami degradasi lingkungan akibat penambangan pasir yang mengakibatkan kerentanan pesisir di Lontar semakin tinggi. Salah satu akibat dari penambangan pasir secara besar-besaran di Lontar adalah terjadinya erosi dan akresi pantai di kawasan penambangan pasir dan di sekitarnya. Akresi adalah perubahan garis pantai menuju laut lepas karena adanya proses sedimentasi. Tercampur lumpur akibat penambangan pasir sehingga dapat berpotensi terhadap penurunan kualitas air, dimana kekeruhan air yang kontinyu dan atau tersuspensinya biogeokimia yang lain (Prihantono et al 2014).

\section{e. Tanjung Kait}

Berdasarkan observasi langsung di Tanjung Kait diketahui terdapat tambak idle yang tidak termanfaatkan maksimal oleh masyarakat setempat. Namun, untuk 
menentukan suatu lokasi bisa dijadikan sebagai tambak garam harus mengetahui indeks kerentanan pesisir sebagai acuan dalam memberikan rekomendasi lokasi penggaraman. Variable fisik yang berinteraksi antara lain geomorfologi pantai, kelerengan atau kemiringan pantai, kenaikan muka air laut laju perubahan garis pantai (abrasi dan akresi) dan gelombang laut.

\section{f. Tanjung Pasir}

Tanjung Pasir merupakan pantai wisata yang dikelola oleh TNI AL Kabupaten Tangerang. Berdasarkan hasil observasi, diketahui telah mengalami penurunan lingkungan akibat abrasi pantai dan terjadinya penurunan kualitas perairan tersebut diakibatkan aktivitas wisata serta adanya pengaruh dari wilayah lainnya.

Pada saat angin barat dan timur terjadi di Tanjung Pasir mengakibatkan perairannya sangat keruh dan terjadinya erosi dan akrasi. Selain itu, Perairan Tanjung Pasir berbatasan dengan Perairan Jakarta yang menyebabkan rentannya terhadap pencemaran.

Secara umum, kegiatan dalam pembuatan garam dibagi menjadi empat, yaitu penampungan air, peminihan, kristalisasi serta perawatan dan pemantauan (Adi et al 2007).

a) Penampungan air laut
Tahapan pembuatan garam di mulai dengan menampung air laut. Pada tahap ini diharapkan air laut sebagai bahan baku utama bebas dari limbah dan jauh dari muara sungai (kurang dari $10 \mathrm{~km}$ ) yang bertujuan untuk menghindari terjadinya pengkristalan air laut dari tepi pantai ke lokasi penggaraman. Tambak garam di Desa Cikeusik berada jauh dari muara sungai. Proses pengambilan air laut dapat melalui pompa atau menggunakan kincir.

Pada bak penampungan diharapkan salinitas sudah lebih dari 35 ppt $\left(3,5^{\circ} \mathrm{Be}\right)$ dan terjadi pengendapan partikel lumpur yang ada dalam air laut sekaligus terjadi evaporasi, sehingga terjadi kenaikan salinitas berkisar antara $50 \mathrm{ppt}\left(5^{\circ} \mathrm{Be}\right)-100 \mathrm{ppt}(10$ ${ }^{\circ} \mathrm{Be}$ ) yang kemudian dipindahkan ke kolam peminihan I. Di dalam bak penampungan ini pekerjaan Kesap Guluk (K/G) pertama dilakukan setelah air meja mencapai salinitas $40 \mathrm{ppt}-60 \mathrm{ppt}\left(4^{\circ} \mathrm{Be}-6^{\circ} \mathrm{Be}\right)$.

b) Peminihan

Air laut yang keluar dari bak penampungan diharapkan bersalinitas lebih dari 50 ppt $\left(5^{\circ} \mathrm{Be}\right)$ dimasukkan ke dalam peminihan I. Kolam peminihan diharapkan terjadi pengendapan partikel lumpur kembali serta sebagian senyawa Magnesium, Kalsium lumpur kembali serta sebagian 
senyawa Magnesium, Kalsium dan Sulfat mengendap. Pada proses peminihan I diharapkan terjadi kenaikan salinitas mencapai 150 ppt $\left(15^{\circ} \mathrm{Be}\right)$. Kemudian air disalurkan pada bak peminihan II. Dalam peminihan II ini pengendapan juga terjadi sehingga air laut (brine) yang akan masuk ke dalam kolam kristalisasi I sudah tinggi dengan senyawa $\mathrm{NaCl}$ yang akan menjadi garam. Pada kolam kristalisasi II dengan salinitas sudah mencapai $>150 \operatorname{ppt}\left(15^{\circ} \mathrm{Be}\right)$ dilakukan pekerjaan Kesap Guluk II (K/G II) yang dilakukan setelah air meja mencapai salinitas $180 \mathrm{ppt}-220 \mathrm{ppt}\left(18^{\circ} \mathrm{Be}-22^{\circ} \mathrm{Be}\right)$ dan meja/kolam diatasnya dilakukan Kesap Guluk II (K/G II) dengan perlakuan yang sama.

\section{c) Kristalisasi}

Air laut yang diasumsikan sudah mengandung $\mathrm{NaCl}$ pekat dari bak peminihan II dengan salinitas mencapai $250 \mathrm{ppt}\left(25^{\circ} \mathrm{Be}\right)$ masuk ke dalam kolam kristalisasi atau meja garam. Pada kolam ini diharapkan $\mathrm{NaCl}$ yang terkandung dalam air laut sebesar $>98 \%$. Pada kolam kristalisasi atau meja garam I ini diharapkan salinitas naik menjadi 280 ppt $\left(28^{\circ} \mathrm{Be}\right)$. Kemudian air dikirim masuk ke meja kristal/garam II. Kolam kristalisasi II atau meja garam II $\mathrm{NaCl}$ yang terendapkan $>72 \%$ dan air yang masih ada dikenal sebagai air bittern. Pada proses kristalisasi perlu diperhatikan pemeliharaan meja garam dan dilakukan aflak (perataan permukaan dasar garam. Proses kristalisasi dipengaruhi oleh beberapa faktor, antara lain suhu udara, kelembaban, intensitas cahaya, suhu air dan $\mathrm{pH}$ (Arwiyah et al 2015).

\section{d) Perawatan dan Pemantauan}

Selama proses penggaraman diharapkan selalu ada pemantauan dan perawatan dari lokasi penggaraman, baik pemantauan dari masuknya debit air laut ke dalam kolam penampungan dan kenaikan salinitas pada tiap-tiap kolam penggaraman. Kegiatan perawatan dan pemantauan sebaiknya dilakukan setiap hari sehingga dapat mempercepat proses penggaraman.

\section{Inovasi Teknologi}

\section{Produksi Garam dengan Sistem Termal}

Garam rakyat tradisional pada umumnya dibuat dengan cara menimba air laut dengan menggunakan kincir atau secara manual yaitu dengan menimba air laut kemudian dimasukkan ke dalam ladang penguapan sehingga langsung dihasilkan kristal garam. Kadar garam yang dihasilkan berkualitas rendah yaitu di bawah 90\%. Hal ini dikarenakan petani garam masih menggunakan model terasering pada tambak 
Tabel 3 Fungsi kolam pada tambak TUF

\begin{tabular}{|c|c|c|}
\hline No & Jenis Kolam & Fungsi \\
\hline 1 & Penampungan (reservoir) & $\begin{array}{l}\text { Tempat awal untuk menampung air laut dengan kadar } \\
\text { kepekatan } 1-5^{\circ} \mathrm{Be} \text { dan mengendapkan material organic }\end{array}$ \\
\hline 2 & Peminihan (condesor) & $\begin{array}{l}\text { Merupakan tempat proses penuaan air laut dengan evaporasi } \\
\text { sinar matahari. Pada sistem TUF, dibuat dalam bentuk } \\
\text { petakan-petakan berseri (ulir) semacam saluran berukuran } \\
\text { seragam dengan lebar } 3 \mathrm{~m} \text {. Pada kolam peminihan } \\
\text { berlangsung penuaan air laut menjadi } 25^{\circ} \mathrm{Be} \text {. Air tua (brine) } \\
\text { dengan kepekatan } 25^{\circ} \text { Be merupakan bahan baku garam } \\
\text { yang akan dialirkan ke dalam meja kristal (crytalizers) }\end{array}$ \\
\hline 3 & Kanal brine & $\begin{array}{l}\text { Merupakan saluran kecil dan petakan tempat menampung } \\
\text { brine densitas } 25^{\circ} \mathrm{Be} \text { yang siap dikristalkan }\end{array}$ \\
\hline 4 & Meja kristal (crystalizers) & $\begin{array}{l}\text { Merupakan petakan - petakan dimana terjadi kristalisasi } \\
\text { brine menjadi Kristal garam }\end{array}$ \\
\hline
\end{tabular}

Sumber: (Suhelmi et al 2013)

garamnya. Selain itu, petani tambak masih mengandalkan faktor alam yaitu dengan penguapan yang dibantu oleh sinar matahari sehingga apabila cuaca tidak mendukung (hujan) maka produksi garam akan berhenti. Untuk mengatasi permasalahan tersebut dapat menggunakan inovasi teknologi produksi dengan sistem termal.

Prinsip pembuatan garam dengan menggunakan sistem termal adalah meningkatkan konsentrasi $\mathrm{NaCl}$ air laut dengan memisahkan air murninya. Efisiensi pemisahan air murni dari air laut menggunakan cara termal dan penurunan titik didih. Cairan yang berada dalam tekanan tinggi akan memiliki titik didih lebih tinggi jika dibandingkan dengan cairan pada tekanan rendah. Pada proses penguapan, tekanan uap jenuh (saturated vapor pressure (SVP) atau vaporpressure) lebih kecil dari tekanan udara luar. Sementara proses mendidih dapat tercapai jika tekanan uap jenuh (SVP) sama dengan tekanan tekanan luar. Terdapat dua prinsip pada alat pembuatan garam dengan menggunakan sistem termal, yaitu dengan sistem perebusan 
dan pengovenan (P3SDLP 2013).

a) Sistem perebusan

Prinsip dasar pada sistem perebusan yaitu optimasi pelepasan air murni dalam air laut menggunakan media rebus tertutup dibantu recervoir destilator serta centrifugal blower vacuum. Pengoperasian alat ini dimulai dengan tabung rebus bervolume 1000 liter diisi air laut bersalinitas 3\% sebanyak 750 liter. Air direbus dengan barner LPG berkalori $700{ }^{\circ} \mathrm{C}$ dapat mendidih dalam waktu 3 jam dengan pengurangan volume 113 liter tiap jam. Selanjutnya,air murni diambil melalui tabung reservoir.

\section{b) Sistem pengovenan}

Prinsip sistem pengovenan adalah mengeringkan garam hasil spinner dengan kadar air $( \pm 30 \%)$ dengan cara mengadopsi dari penjemuran alam dibawah terik matahari. Cara tersebut diadaptasi menjadi pemanasan disertai dengan sirkulasi udara di dalam ruang oven. Untuk menghindari gosong dan bau digunakan heat charger didorong dengan kipas sirkulasi. Penggunaan heat charger memungkinkan penggunaan oli bekas, solar dan briket sebagai bahan pemanas tanpa terpengaruh bau bahan di dalam ruang ovennya. Stabilitas panas dan humidity dalam ruang oven terkontrol melalui buka tutup inlet/outlet ruang oven serta kontrol panas dalam heat charger

Hasil penelitian yang dilakukan oleh P3SDLP (2013) menunjukkan bahwa pembuatan sistem garam dengan menggunakan sistem termal menghasilkan kandungan $\mathrm{NaCl}$ dengan kadar low $(<40 \%)$, medium (40 - 90\%) dan high (>90\%) serta dapat mengurangi kadar air dalam garam $( \pm$ $30 \%$ ) menjadi e" 7\% diperlukan waktu 30 menit. Keunggulan dari sistem ini adalah menggunakan sistem "boiler" untuk mempercepat waktu proses peminihan air laut, dengan pemanfaatan energi termal yang tidak tergantung pada lahan dan iklim. Benih garam dapat diproduksi dengan mengurangi ketergantunganterhadap cuaca agar produksi garam dapat dilakukan sepanjang tahun dan ketersediaan benih garam berkualitas sebagai bahan baku proses kristalisasi.

\section{Produksi Garam dengan Tambak Ulir}

\section{Filter}

Kualitas garam sangatlah ditentukan oleh teknologi yang digunakan oleh petambak garam. Pada saat ini, banyak para petambak memproduksi garam dengan teknologi sederhana sehingga menghasilkan kualitas garam berkualitas $3(\mathrm{NaCl}<94 \%)$. Pembaharuan teknologi produksi untuk peningkatan kualitas produksi garam harus dilakukan. Adapun beberapa teknologi dalam 
pembuatan garam antara lain penggunaan zat aditif berupa ramsol (Aris 2011; Amelia 2013), penggunaan membran atau terpal sebagai alas pada meja garam (Mustofa \& Turjono 2015). Setiap teknologi di atas mempunyai beberapa permasalahan dalam penerapannya di masyarakat, misalnya penerapan ramsol atau zat aditif hanya dapat memutihkan Kristal garam dan memerlukan biaya produksi yang tinggi (Kadarwati et al 2010). Salah satu teknologi yang dapat diterapkan adalah teknologi pembuatan garam dengan Tambak Ulir Filter (TUF).

Tambak Ulir Filter (TUF) merupakan suatu teknologi yang membutuhkan perubahan struktur tambak menjadi ulir. Adapun prinsip utama dalam pembuatan garam dengan menggunakan TUF yaitu evaporasi air laut dengan bantuan sinar matahari dialirkan melalui petakan-petakan berseri dalam proses penuaannya dan dalam proses tersebut ditambahkan material alam (ijuk, kelapa, dan batu alam) yang digunakan sebagai filter untuk purifikasi air tua (Suhelmi et al 2013). Adapun persyaratan teknis dan kriteria pada tambak TUF ini adalah sebagai berikut (Dir. PMPPU 2014):

a) Petak kristalisasi memanjang searah dengan arah angin;

b) Petakan lahan tambak dibuat menurut elevasi; c) Sumber air harus cukup, lancer dan bersih dengan menempatkan filter pada setiap petak;

d) Ukuran petakan disesuaikan dengan luas lahan yang tersedia, dengan persentase sebagai berikut:Kolam penampungan besar $32 \%$, Kolam ulir besar $17 \%$, Bak penampungan $2 \%$,Ulir kecil 19\%,Bak penampungan 2\%,Kolam kristalisasi 25\%,Gudang $1 \%$ dan jalan $2 \%$.

e) Ketinggian air di petak ulir besar dan kecil $5 \mathrm{~cm}$ dan petak kristalisasi $10-$ $15 \mathrm{~cm}$;

f) Sebelum dipanen harus ada sisa air di petak kristalisasi $1-2 \mathrm{~cm}$

Proporsi antara reservoir, kolam peminihan dan meja kristalisasi memperhitungkan 2 aspek yaitu luas area dan volume air tua (brine) yang dihasilkan dengan melihat kapasitas volume masing-masing kolam. Komposisi perbandingan antara luas kolam penampungan, kolam peminihan dan kristalisasi pada tambak TUF adalah 25\%:25\%:50\%, dan untuk rasio volume kolam pada tiap-tiap kolam adalah 75\% kolam penampungan : $14 \%$ kolam peminihan : $11 \%$ meja kristalisasi. Rasio volume kolam dapat menggambarkan ketersediaan brine sebagai bahan baku garam (Santosa 2014). 
Konstruksi tambak TUF memiliki perbedaan apabila dibandingkan dengan kontruksi tangga dan konstruksi kompleks meja, yaitu pada tambak TUF menggunakan konstruksi tangga pada kolam ulir yang dibuat dengan kemiringan 1-2 derajat dan pengaliran brine dilakukan secara gravitasi dari kolam ulir ke tempat penampungan brine. Teknik ulir filter menerapkan system bertahap pada proses penuaan air laut dengan membagi sistem ulir menjadi dua bagian, yaitu sistem ulir besar dan sistem ulir kecil. Penggunaan ulir besar dan ulir kecil dapat disesuaikan dengan kondisi dan luas lahan. Penggunaan kolam ulir diduga berkontribusi terhadap percepatan ketersediaan brine yang siap dikristalkan $\left(20-25{ }^{\circ} \mathrm{Be}\right)$, sehingga dapat meningkatkan kualitas produksi dalam suatu periode musim panen garam. Pada prinsipnya, penggunaan saluran pada tambak konvensional maupun kolam ulir pada tambak TUF bertujuan untuk proses penguapan sehingga dapat meningkatkan kuantitas produksi garam. Adapun tahap pembuatan tambak garam sistem TUF.

\section{Pemanfaatan Limbah Pembuatan}

\section{Garam (Bittern) Sebagai Bahan Baku}

\section{Industri}

Bittern atau limbah dari pembuatan garam merupakan hasil samping dari pembuatan garam berupa sisa cairan pekat yang oleh petani garam tradisional belum dimanfaatkan secara maksimal dan dibuang ke laut sehingga terjadi pencemaran. Hal ini dikarenakan petambak garam menganggap bittern sudah tidak ada nilainya dan mempunyai nilai Be (derajat Beume) di atas $29^{\circ}$ Be serta tidak dapat digunakan lagi dalam pembuatan garam. Namun, oleh beberapa petambak garam menggunakan kembali bittern yang dihasilkan ke dalam air laut atau air tua dengan densitas $\pm 10^{\circ} \mathrm{Be}$ untuk mempercepat penuaan air sehingga mempercepat pembuatan garam. Dalam proses tersebut, dapat menyebabkan terikutnya mineral lain (zat pengotor/impurities) dalam garam terbentuk dikarenakan di dalam bittern kandungan $\mathrm{Na}$ (natrium) lebih relatif rendah dibandingkan kandungan mineral lain.

Selain natrium $(\mathrm{Na})$, mineral lain yang terkandung di dalam bittern antara lain Mg (Magnesium), K (Kalium) dan $\mathrm{Ca}$ (Calsium) (Hapsari 2008). Suhelmi et al (2013) menambahkan untuk menghasilkan 1 ton garam dibutuhkan $50 \mathrm{~m}^{3}$ air laut dan sebagai produk sampingan berupa bittern sekitar $1,9 \mathrm{~m}^{3}$.

Magnesium adalah salah satu kandungan mineral terbesar di dalam bittern. Apabila bittern diolah dengan menggunakan 
soda api $(\mathrm{NaOH})$ dan air maka diperoleh $\mathrm{Mg}(\mathrm{OH})_{2}$ atau magnesium hidroksida. Proses selanjutnya dilakukan pemisahan padatan magnesium dengan menggunakan mesin pemutar cepat dan oven pengering. Hasil yang diperoleh dari teknologi tersebut mampu mengolah $200 \mathrm{~L}$ bittern menjadi padatan magnesium sebanyak $21 \mathrm{~kg}$ dalam waktu 3 hari kerja (Suhelmi et al 2013). Berdasarkan penelitian yang dilakukan oleh P3SDLP (2014) diperoleh pengolahan bittern melalui penambahan soda api $1 \mathrm{M} \mathrm{(4 \% )} \mathrm{dengan} \mathrm{laju}$ $30 \mathrm{~mL} / \mathrm{min}$ (untuk kadar $\mathrm{Mg}$ dalam bittern 3,9\%) dan dicuci dengan akuades dapat memberikan produk $\mathrm{Mg}(\mathrm{OH})_{2}$ dengan kadar $80 \%$ dan berstruktur heksagonal. Magnesium hidroksida dapat bermanfaat sebagai bahan aktif antasida dalam farmakologi dan bahan tahan api dalam industri.

\section{KESIMPULAN DAN REKOMENDASI}

\section{Kesimpulan}

Wilayah perairan utara Provinsi Banten memiliki potensi untuk pengembangan produksi garam. Potensi tersebut ditunjukkan dari hasil pengujian kualitas air dan kajian wilayahnya terutama tambak-tambak yang sudah idle. Pengembangan produksi garam di Provinsi Banten perlu diberikan sentuhan inovasi teknologi agar dapat meningkatkan produktivitas dan kualitas garam yang dihasilkan baik dan sesuai Standar Nasional Indonesia (SNI). Inovasi teknologi yang sesuai dengan wilayah Banten adalah produksi garam dengan sistem termal dan Teknologi Ulir Filter (TUF). Selain itu, pengolahan limbah dari produksi garam juga dilakukan melalui teknologi Bittern yang dapat dijadikan sebagai bahan baku industri.

\section{Rekomendasi}

1. Peran serta Pemerintah Pusat dan Daerah (Pemda) perlu ditingkatkan dalam pengembangan tambak garam di Provinsi Banten.

2. Koordinasi antara petambak garam dengan Pemda maupun antar Pemda penting untuk dilakukan sehingga produktivitas dan kualitas garam dapat ditingkatkan.

3. Perlu dilakukan peningkatan sumberdaya manusia (petambak garam) agar dapat menerapkan teknologi terkini.

\section{DAFTAR PUSTAKA}

Adi TR, Supangat A, Sulistyo B, Muljo B, Amarullah H, Prihadi TH, Sudarto, Soentjahjo E \& Rustam A. 2007. Panduan Pengembangan Usaha Terpadu Garam dan Artemia. Jakarta: Pusat Riset Wilayah Laut dan Sumberdaya Nonhayati, Badan Riset Kelautan dan Perikanan. 
Arwiyah, Zainuri M \& Efendy M. 2015. Studi kandungan $\mathrm{NaCl}$ di dalam air baku dan garam yang dihasilkan serta produktivitas lahan garam menggunakan media meja garam yang berbeda. Jurnal Kelautan 8 (1): 1 - 9.

Assadad L \& Utomo BSB. Pemanfaatan garam dalam industri pengolahan produk perikanan. Squalen 6 (1): 26 - 37.

[Dir. PMPPU] Direktorat Pemberdayaan Masyarakat Pesisir dan Pengembangan Usaha. 2014. Bahan Tayang Pembekalan Tenaga Pedamping Pugar Tahun 2014. Jakarta: Direktorat Jendral Kelautan Pesisir dan Pulau-Pulau Kecil, Kementerian Kelautan dan Perikanan.

Harjadi B, Nugroho AW, Abdiyani S, Miardini A \& Octavia D. 2014. Pedoman Teknis Pengelolaan Lahan Bermasalah Pantai Berpasir Dengan Cemara. Jakarta: Badan Penelitian dan Pengembangan Kehutanan, Kementerian Kehutanan. $103 \mathrm{hlm}$.

Kadarwati U, Ratnawati HI, Prabawa FY, Hidayat W, Hendrajana B \& Dewi LC. 2010. Studi Potensi Bittern Pada Tambak Garam Rakyat [LAPORAN AKHIR PENELITIAN]. Jakarta: Pusat Penelitian dan Pengembangan Sumberdaya Pesisir, Badan Penelitian dan Pengembangan, Kementerian Kelautan dan Perikanan.

Kurniawan T \& Erlina MD. 2012. Peningkatan Produksi Garam melalui Penerapan Teknologi Ulir Filter (TUF) di Kabupaten Cirebon, Jawa Barat. Prosiding Seminar Nasional Inovasi Teknologi Pengolahan Produk dan Bioteknologi Kelautan dan Perikanan IV;
Jakarta, Indonesia.

Manadiyanto \& Arthatiani FY. 2011. Pemanfaatan Limbah Pembuatan Garam Sebagai Upaya Peningkatan Pendapatan Petambak Garam Di Pulau Madura [Laporan]. Jakarta: Balai Besar Riset Sosial Ekonomi Kelautan dan Perikanan, Kementerian Kelautan dan Perikanan.

Mefriyanto F. 2014. Perubahan Kadar $\mathrm{NaCl}$ Garam Rakyat selama Masa Penyimpanan di Dalam Gudang [SKRIPSI]. Madura: Jurusan Ilmu Kelautan, Universitas Trunojoyo.

Mustofa \& Turjono E. 2015. Analisis optimalisasi terhadap aktivitas petani garam melalui pendekatan hulu hilir Di penambangan Probolinggo. Jurnal Wiga $5(1): 46-57$.

[P3SDLP] Pusat Penelitian dan Pengembangan Sumber Daya Laut dan Pesisir. 2014. Laporan Ringkas Hasil Penelitian dan Pengembangan Kelautan dan Perikanan Tahun 2013. Jakarta: Badan Penelitian dan Pengembang Kelautan dan Perikanan, Kementerian Kelautan dan Perikanan.

[P3SDLP] Pusat Penelitian dan Pengembangan Sumber Daya Laut dan Pesisir. 2013. Laporan Ringkas Hasil Penelitian dan Pengembangan Kelautan dan Perikanan Tahun 2012. Jakarta: Badan Penelitian dan Pengembang Kelautan dan Perikanan, Kementerian Kelautan dan Perikanan.

[P3SDLP] Pusat Penelitian dan Pengembangan Sumber Daya Laut dan Pesisir. 2005. Informasi Iklim dan Cuaca Untuk Tambak Garam. Jakarta: Badan 
Penelitian dan Pengembang Kelautan dan Perikanan, Kementerian Kelautan dan Perikanan.

Prihantono J, Troa RA, Dewi LC, Dillenia I \& Triarso E. 2014. Kajian Dampak Penambangan Pasir Laut Pantai Utara Banten Untuk Reklamasi Teluk Jakarta Terhadap Sumberdaya Laut dan Pesisir. Pusat Penelitian dan Pengembangan Sumber Daya Laut dan Pesisir. http:// p3sdlp.litbang.kkp.go.id/index.php/en/ litbang/sumber-daya pesisir/2014/600kajian-dampak-penambangan-pasir-lautpantai-utara-banten-untuk-reklamasiteluk-jakarta-terhadap-sumberdaya-lautdan-pesisir. [diakses pada tanggal 16 Agustus 2016].

Riley JP \& Skirrow G. 1975. Chemical Oceanography V $42^{\text {nd }}$ (ed). San Fransisco: Academic Press.

Santosa I. 2014. Pembuatan garam menggunakan kolam terhadap kolam kedap air berukuran sama. Spektrum Industri 12 (1): 85 - 91.

Suhelmi IR, Widjanarko E, Triwibowo H, Sagala SL, Najid A, Widodo AW \& Bramawanto R. 2013. Garam Madura, Tradisi dan Potensi Usaha Garam Rakyat. Jakarta: Pusat Penelitian dan Pengembangan Sumber Daya Laut dan Pesisir, Badan Penelitian dan Pengembangan Kelautan dan Perikanan, Kementerian Kelautan dan Perikanan. 109 hlm.

Thieler E.R \& Hammar-Klose ES. 2000. National assessment of coastal vulnerability to sea - level rise; Preliminary results for the US Atlantic Coast: US Geological Suvey Open File Reports. 